\title{
ANALISIS FAKTOR YANG BERHUBUNGAN DENGAN KINERJA BIDAN DESA DALAM PELAYANAN ANTENATAL DI WILAYAH KERJA PUSKESMAS PASAR UJUNG BATU KABUPATEN PADANG LAWAS TAHUN 2015
}

\author{
Elvi Diana Siregar \\ Akbid Baruna Husada Sibuhuan
}

\begin{abstract}
Antenatal care is health care by professionals to the mother during pregnancy. Village midwife are health workers who are closest to the people, and most are expected to know the state of health of pregnant women, birth mothers and babies in the village. Performance midwife may also be influenced by many factors, including the characteristics of the midwife, internal factors, external and motivation. This research aimed to analyze factors related to the performance of midwives in antenatal care health centers in the region at Pasar Ujung Batu Sub-District, Padang Lawas District. This research was an analytical-survey by using cross sectional study design. The population were all is all midwives in the working area of Pasar Ujung Batu Health Centre, as many as 40 people. All of population were being the sample. Data collected by using questionnaire, and analyzed by multiple logistic regression at 95\% Confidence Interval.The research showed that the midwife who had a good performance as much as $37.5 \%$ and the poorer performers were $62.5 \%$. Statistically, the results also showed that the characteristics (age, marital status), internal factors (income and socio-cultural), external factors (incentives and coaching) and motivation (sense) is not related to the performance of midwives. While the knowledge, skills, infrastructure and business partners associated with the performance of midwives in the ANC. It is suggested midwives in order to improve its performance by increasing knowledge of the ANC, complementary means of infrastructures that support, establish good cooperation with partners and provide counseling to pregnant women about the importance of ANC to get pregnant women to get the ANC even though the mother is not impaired pregnancy so that mother and fetus remains health.
\end{abstract}

Keywords : Performance, Antenatal Care Service, Characteristics, Internal, External, Motivation

\section{PENDAHULUAN}

Pelayanan antenatal adalah pelayanan kesehatan oleh tenaga profesional (dokter spesialis kebidanan, dokter umum, bidan, pembantu bidan dan perawat bidan) untuk ibu selama masa kehamilannya, sesuai standar minimal pelayanan 5T yaitu timbang berat badan, ukur tinggi badan, ukur tekanan darah, pemberian imunisasi TT, ukur fundus uteri dan pemberian tablet besi minimal 90 tablet selama masa kehamilannya (Saputra, 2010).

Tenaga bidan desa merupakan tenaga kesehatan yang paling dekat dengan masyarakat, serta diharapkan paling mengetahui keadaan kesehatan ibu hamil, ibu bersalin dan bayi di desa. Melihat besarnya bahwa tanggung jawab yang harus diemban oleh setiap bidan desa ini perlu kesadaran yang tinggi akan pelaksanaan tugas (Suyudi, 2001).

Kemampuan dan keberhasilan kerja bidan desa di desa dapat diukur dari jumlah cakupan pertolongan persalinan di setiap desa. Berdasarkan laporan puskesmas pasar ujung batu bahwa pertolongan ibu melahirkan yang dilayani petugas kesehatan di wilayah kerja puskesmas
Pasar Ujung Batu sebesar 68\%. Data lainnya menunjukkan bidan desa di wilayah kerja puskesmas Pasar Ujung Batu sebesar adalah cakupan kunjungan pemeriksaan kehamilan $(\mathrm{K} 1=64 \%$ dan $\mathrm{K} 4=58 \%)$.

\section{PERMASALAHAN}

Berdasarkan latar belakang di atas, maka yang menjadi permasalahan adalah belum diketahuinya bagaimana kinerja bidan desa di wilayah kerja puskesmas Pasar Ujung Batu.

\section{TUJUAN UMUM}

Berdasarkan latar belakang di atas, maka yang menjadi permasalahan adalah belum diketahuinya bagaimana kinerja bidan desa di wilayah kerja puskesmas Pasar Ujung Batu. 


\section{TUJUAN KHUSUS}

1. Untuk mengetahui hubungan karakteristik (umur, status perkawinan, dan pengetahuan) dengan kinerja bidan desa diwilayah kerja puskesmas Pasar Ujung Batu

2. Untuk menganalisis hubungan faktor internal (penghasilan, keterampilan, sosial Budaya) dengan kinerja bidan di wilayah kerja puskesmas Pasar Ujung Batu

3. Untuk menganalisis hubungan faktor eksternal (Sarana prasarana, mitra kerja, insentif dan pembinaan) dengan kinerja bidan di wilayah kerja puskesmas Pasar Ujung Batu

4. Untuk menganalisis hubungan motivasi (kebutuhan rasa aman dan rasa memiliki) dengan kinerja bidan di wilayah kerja puskesmas Pasar Ujung Batu

5. Untuk menganalisis faktor yang paling dominan mempengaruhi kinerja bidan desa di wilayah kerja puskesmas Pasar Ujung Batu

\section{HIPOTESIS}

Hipotesis pada penelitian ini adalah:

1. Ada hubungan karakteristik (umur, status perkawinan, dan pengetahuan) dengan kinerja bidan desa diwilayah kerja puskesmas Pasar Ujung Batu

2. Ada hubungan hubungan faktor internal (penghasilan, keterampilan, sosial Budaya) dengan kinerja bidan di wilayah kerja puskesmas Pasar Ujung Batu

3. Ada hubungan faktor eksternal (Sarana prasarana, mitra kerja, insentif dan pembinaan) dengan kinerja bidan di wilayah kerja puskesmas Pasar Ujung Batu

4. Ada hubungan motivasi (kebutuhan rasa aman dan rasa memiliki) dengan kinerja bidan di wilayah kerja puskesmas Pasar Ujung Batu

\section{MANFAAT PENELITIAN}

1. Bagi Dinas Kesehatan Kabupaten Padang Lawas sebagai masukan dalam meningkatkan kinerja bidan desa dengan diketahuinya faktor-faktor yang berhubungan dengan kinerja bidan desa.

2. Bagi puskesmas Pasar Ujung Batu sebagai informasi dalam evaluasi dan pengawasan terhadap kinerja bidan desa dalam pelayanan ANC sehingga dapat dilakukan perbaikan guna mewujudkan penurunan AKI

\section{TINJAUAN PUSTAKA}

\section{Kinerja}

Kinerja adalah merupakan gambaran mengenai pencapaiana pelaksanaan suatu program kegiatan atau kebijakan dalam mewujudkan sasaran, tujuan, visi dan misi organisasi yang dituangkan melalui perencanaan strategis suatu organisasi. Kinerja atau performance juga dapat diartikan sebagai hasil kerja yang dicapai oleh seseorang atau sekolempok orang dalam suatu organisasi baik secara kuantitatif maupun kualitatif, sesuai dengan kewenangan dan tugas tanggung jawab masing-masing dalam upaya mencapai tujuan organisasi bersangkutan secara illegal, tidak melanggar hukum dan sesuai dengan moral maupun etika (Moeheriono, 2012).

\section{Kinerja Bidan Desa}

Kinerja bidan desa sesuai dalam buku panduan bidan di tingkat desa dapat di ukur melalui keberhasilan bidan dalam melaksanakan tugas pokok dan fungsi bidan desa yaitu (a) Meningkatkan cakupan dan mutu pelayanan kesehatan ibu hamil, pertolongan persalinan, perawatan nifas, kesehatan bayi dan anak balita serta pelayanan dan konseling pemakaian kontrasepsi serta keluarga berencana melalui upaya strategis antara lain : Posyandu dan Polindes, (b) Menjaring seluruh kasus risiko tinggi ibu hamil, bersalin, nifas dan bayi baru lahir untuk mendapatkan penanganan memadai sesuai kasus dan rujukannya, (c) Meningkatkan peran serta masyarakat dalam pembinaan kesehatan ibu dan anak di wilayah kerjanya, (d) Meningkatkan perilaku sehat pada ibu, keluarga dan masyarakat yang mendukung upaya penurunan angka kematian ibu dan angka kematian bayi.

\section{Antenatal Care (ANC)}

ANC merupakan pemeriksaan ibu hamil baik fisik dan mental serta menyelamatkan ibu dan anak dalam kehamilan, persalinan dan masa nifas sehingga mampu menghadapi persalinan, kala nifas, persiapan pemberiaan ASI dan kembalinya kesehatan reproduksi secara wajar (Wiknjosastro, 2005.; Manuaba, 2008).

\section{JENIS PENELITIAN}

Jenis penelitian ini adalah penelitian survei yang bersifat analitik dengan menggunakan desain sekat silang (Cross Sectional) untuk menganalisis faktor yang berhubungan dengan kinerja bidan dalam pelayanan Antenatal di wilayah kerja puskesmas Pasar Ujung Batu.

\section{LOKASI PENELITIAN}

Penelitian ini dilaksanakan di wilayah kerja Puskesmas Pasar Ujung Batu Kabupaten Padang Lawas.

\section{WAKTU PENELITIAN}

Penelitian ini dilaksanakan pada bulan JuniDesember 2015.

\section{POPULASI}

Populasi dalam penelitian ini adalah seluruh bidan desa (bidan PTT) yang ada di wilayah kerja puskesmas Pasar Ujung Batu sebanyak 40 orang. 


\section{SAMPEL}

Sampel dalam penelitian ini adalah total populasi yaitu seluruh bidan desa yang ada di wilayah kerja puskesmas Pasar Ujung Batu yakni sebanyak 40 orang

\section{HASIL DAN PEMBAHASAN}

\section{Hubungan Umur terhadap Kinerja Bidan Desa dalam Pelayanan ANC}

Hasil penelitian tentang variabel umur ditemukan bidan desa dengan usia $>30$ tahun dengan proporsi Kinerja Bidan Desa dalam Pelayanan ANC yang baik hanya 26,3\% dan hasil uji statistik Chi square menunjukkan variabel umur nilai $\mathrm{p}=0,165>\alpha(0,05)$ maka tidak berhubungan dengan kinerja bidan desa.

Hasil penelitian ini tidak sejalan dengan penelitian Syaelendra (2001) yang menunjukkan bahwa ada hubungan umur terhadap kinerja bidan desa $(\mathrm{p}<0,05)$, karakteristik umur responden pada penelitian ini sebagian besar $(66 \%)$ berumur $>25$ tahun yang artinya rata-rata responden sudah berpengalaman dan sudah dianggap dewasa.

Menurut Suganda (1994) dalam Syaelendra (2001) mengutarakan bahwa bidan desa adalah seorang perempuan muda yang berumur berkisar 19-24 tahun yang masih dalam masa transisi akhir dalam pengembangan kepribadiannya. Disatu pihak ia masih remaja sedangkan dipihak lain dia harus berperilaku seperti orang dewasa dalam melayani ibu hamil dan melahirkan

\section{Hubungan status perkawinan dengan Kinerja Bidan Desa dalam Pelayanan ANC}

Status perkawinan merupakan salah satu prediktor pada kinerja bidan desa dalam pelayanan ANC. Hasil penelitian tentang variabel status perkawinan pada bidan dengan status perkawinan menikah dengan proporsi Kinerja Bidan Desa baik sebesar 42,4\%. Uji statistik dengan uji chi-square diperoleh bahwa $\mathrm{p}=0,162<\alpha(0,05)$ berarti tidak terdapat hubungan status perkawinan dengan Kinerja Bidan Desa di Wilayah Kerja Puskesmas Pasar Ujung Batu Kabupaten Padang Lawas

Mengacu pada penelitian diatas sejalan dengan penelitian Surani (2008) menyatakan hasil analisis hubungan dengan menggunakan uji chi-square tidak terdapat hubungan yang bermakna antara status perkawinan dengan kinerja bidan desa.

Hubungan status perkawinan dan kinerja menunjukkan bahwa perkawinan itu menuntut tanggung jawab keluarga yang lebih besar, sehingga peningkatan posisi dalam pekerjaan menjadi sangat penting atau mungkin saja karena sudah kawin menjadi rajin bekerja (Siagian, 2000).

\section{Hubungan Pengetahuan terhadap Kinerja Bidan Desa dalam Pelayanan ANC}

Hasil penelitian tentang variabel pengetahuan bidan desa menunjukkan hasil pengetahuan baik dengan kinerja yang baik sebesar 45,5\%. Uji statistik dengan uji Chi-square diperoleh bahwa nilai $\mathrm{p}(0,024)$ $<\alpha(0,05)$ berarti terdapat hubungan pengetahuan dengan Kinerja Bidan Desa dalam Pelayanan ANC di Wilayah Kerja Puskesmas Pasar Ujung Batu Kabupaten Padang Lawas. Mengacu pada hasil uji tersebut dapat dijelaskan bahwa semakin baik pengetahuan bidan tentang pelayanan ANC maka akan terjadi peningkatan dalam kinerjanya.

Seseorang yang berpengetahuan baik akan cenderung dapat meningkatkan kinerjanya, hal ini mungkin disebabkan karena seorang bidan yang berpengetahuan baik peduli dengan tugasnya sebagai bidan dan terdapat perhatian terhadap pemberian pelayanan ANC. Pengetahuan yang dimiliki bidan membuat bidan lebih memahami tentang pelayanan ANC sehingga kinerjanya akan menjadi baik pula.

Menurut Bloom dalam Notoatmodjo (2003) mengatakan bahwa pengetahuan merupakan domain yang sangat penting untuk terbentuknya tindakan seseorang. Dimana dalam hal ini seorang bidan tidak akan baik kinerjanya apabila bidan tersebut tidak mengetahui tentang pelayanan antenatal.

Friedman (2005) menyatakan bahwa semakin tinggi tingkat pengetahuan seseorang, maka perilaku akan lebih bersifat langgeng. Dengan kata lain ibu yang tahu dan paham tentang jumlah anak yang ideal, maka ibu akan berperilaku sesuai dengan apa yang ia ketahui.

\section{Hubungan Penghasilan dengan Kinerja Bidan Desa dalam Pelayanan ANC}

Hasil penelitian tentang variabel penghasilan dengan kategori tinggi dengan kinerja baik sebesar $60 \%$ sedangkan penghasilan dengan kategori rendah kinerja baik sebesar 30\%. Uji statistik dengan chi-square diperoleh bahwa nilai $\mathrm{p}(0,090)>\alpha(0,05)$ berarti tidak terdapat hubungan penghasilan dengan Kinerja Bidan Desa dalam Pelayanan ANC di Wilayah Kerja Puskesmas Pasar Ujung Batu Kabupaten Padang Lawas. Mengacu pada hasil uji tersebut dapat dijelaskan bahwa makin tinggi penghasilan dapat menjadi faktor yang menyebabkan meningkatnya kinerja bidan. Berdasarkan hasil penelitian dapat dilihat bahwa penghasilan tinggi dikarenakan pada umumnya bidan mempunyai penghasilan selain dari gaji sebagai bidan desa. Pekerjaan bidan diluar jam kerja juga dapat mendukung terhadap peningkatan penghasilan keluarga.

Penelitian Syaelendra (2001) menyatakan bahwa ada hubungan yang bermakna antara penghasilan dengan kinerja bidan di desa. Hasil penelitiannya juga menyatakan bahwa bidan di desa yang mempunyai penghasilan cukup (tinggi) berpeluang untuk mempunyai kinerja baik 54,03 kali lebih besar dibandingkan bidan di desa yang mempunyai penghasilan tidak cukup (rendah). Pendapat ini didukung oleh pendapat Gilmer (1996) dalam Syaelendra (2001) menyatakan bahwa penghasilan merupakan salah satu faktor yang mempengaruhi kinerja seseorang. 


\section{Hubungan Keterampilan dengan Kinerja Bidan Desa dalam Pelayanan ANC}

Hasil penelitian tentang variabel keterampilan dimana bidan desa memiliki keterampilan dengan proporsi Kinerja Bidan Desa baik sebesar 27,6\%. Uji statistik dengan uji Chi Square diperoleh bahwa nilai $\mathrm{p}=0,035<\alpha(0,05)$ berarti terdapat hubungan keterampilan dengan Kinerja Bidan Desa dalam pelayanan ANC di Wilayah Kerja Puskesmas Pasar Ujung Batu Kabupaten Padang Lawas.

Ketrampilan adalah kemampuan secara teknis atau praktik dalam suatu bidang pekerjaan (Heidrachman,et.al.,2005), menurut Sutrisno (2009) dalam Wanda (2011) ketrampilan adalah sebagai keberadaan dari pengetahuan tentang suatu lingkungan tertentu,pemahaman tentang masalah yang timbul dari lingkungan tersebut dan ketrampilan untuk memecahkan masalah.

Hasil penelitian Dewi (2014) menyatakan faktor keterampilan (skill) X6 terhadap faktor kinerja bidan (Y) dimana jika ingin meningkatkan kinerja maka factor ketrampilan dimana secara teknis dapat melakukan pelayanan antenatal sesuai dengan standar, juga mampu melakukan pencatatan dan pelaporan terkait pekerjaan yang dilakukan sebagai bagian dari standar prosedur kerja yang sehingga dengan pencatatan dan pelaporan yang baik diketahui masalah yang dihadapi oleh bidan didesa dalam pelayanan antenatal.

\section{Hubungan Sosial Budaya dengan Kinerja Bidan Desa dalam Pelayanan ANC}

Hasil penelitian tentang variabel sosial budaya dengan sosial budaya ada dimana proporsi Kinerja Bidan Desa baik sebesar 34,2\%. Uji statistik dengan uji Chi-square diperoleh bahwa p $(0,061)>\alpha(0,05)$ berarti tidak terdapat hubungan sosial budaya dengan Kinerja Bidan Desa dalam Pelayanan ANC di Wilayah Kerja Puskesmas Pasar Ujung Batu Kabupaten Padang Lawas.

Mathis (2002) menyatakan terdapat beberapa faktor yang mempengaruhi kinerja yaitu : lingkungan (ekonomi, politik, sosial, budaya, agama dan teknologi), pasar (potensial, prospek, kompetisi), instansi (reputasi, sumberdaya manusia, kemantapan manajemen, kemantapan teknologi, bentuk pelayanan), dan karyawan (pengalaman, pendidikan dan pelatihan, keterampilan teknis dalam melakukan pekerjaan, kemampuan komunikasi/ adaptasi, komitemen dan sikap dan tingkah laku.

Hasil penelitian juga menunjukkan bahwa bidan menyatakan budaya masyarakat di tempat mereka bekerja terhadap pelayanan ANC khususnya pemeriksaan kehamilan memiliki tradisi/ kebiasaan mengunjungi pelayanan ANC jika mengalami keluhan saja, dan berdasarkan hasil statistik diperoleh yang memiliki sosial budaya mayoritas kinerja bidannya kurang baik $(65,8 \%)$, hal ini dapat disebabkan karena kebiasaan masyarakat tersebut yang kurang memanfaatkan pelayanan ANC disebabkan ketidakteraturan ibu hamil dalam melakukan kunjungan ANC sehingga berakibat terhadap kinerja bidan di desa.

\section{Hubungan Sarana Prasarana dengan Kinerja Bidan Desa dalam Pelayanan ANC}

Berdasarkan hasil penelitian pada variabel sarana prasarana menunjukkan hasil sarana prasarana baik dengan proporsi kinerja bidan desa baik sebesar 52,0\%. Uji statistik dengan uji Chi-Square diperoleh bahwa nilai $\mathrm{p}$ $(0,014)<\alpha(0,05)$ berarti ada hubunga sarana prasarana dengan Kinerja Bidan Desa di Wilayah Kerja Puskesmas Pasar Ujung Batu Kabupaten Padang Lawas. Mengacu pada hasil uji tersebut dapat dijelaskan bahwa adanya sarana prasarana yang baik dapat meningkatan kinerja bidan desa khususnya dalam pelayanan ANC.

Ketersediaan sarana dan prasarana penunjang yang memadai merupakan suatu hal yang sangat penting dalam peningkatan pelayanan ANC, sarana kegiatan pelayanan ANC di antaranya adalah bidan kit, alat pemeriksa Haemoglobin $(\mathrm{Hb})$, alat pemeriksa fisik, obatobatan yang diperlukan serta kelengkapan alat lainnya. Sarana atau alat yang dimiliki bidan untuk pelayanan ANC merupakan alat penunjang dalam bekerja, tanpa sarana seseorang tidak dapat berbuat banyak dalam melakukan kegiatan sesuai dengan fungsinya. Sarana bagi bidan desa merupakan suatu kebutuhan yang vital, tanpa sarana bidan desa tidak bisa berbuat banyak dalam melaksanakan tugas dan fungsinya sebagai seorang bidan desa, disamping fasilitas tambahan lainnya.

Berdasarkan penelitian Syaelendra (2001) menunjukkan bahwa proporsi bidan yang memiliki peralatan (sarana) lebih besar dibanding bidan desa yang tidak mempunyai yaitu masuing-masing $93 \%$ dan $7 \%$. Artinya secara umum responden sudah mempunyai fasilitas dasar dalam melakukan pelayanan ANC. Dari hasil uji statistik kuga memperlihatkan ada hubungan yang bermakna antara perlengkapan kerja dengan kinerja bidan di desa.

\section{Hubungan Mitra Kerja dengan Kinerja Bidan Desa dalam Pelayanan ANC}

Variabel mitra kerja dengan kategori baik dan kinerja bidan desa juga baik sebesar 75,0\% sedangkan mitra kerja dengan kategori tidak baik dan kinerja tidak baik sebesar 78,6\%. Uji statistik dengan uji Chi-square diperoleh bahwa nilai $\mathrm{p}(0,001)<\alpha(0,05)$ berarti terdapat hubungan mitra kerja dengan Kinerja Bidan Desa dalam pelayanan ANC di Wilayah Kerja Puskesmas Pasar Ujung Batu Kabupaten Padang Lawas. Mengacu pada hasil uji tersebut dapat dijelaskan bahwa hubungan antara bidan desa dengan mitra kerjanya dengan baik akan menyebabkan kinerja bidan tersebut semakin baik pula.

Rekan kerja (mitra kerja) adalah seorang atau sekelompok orang yang bekerja dalam satu organisasi baik yang bekerja secara individu maupun kelompok. Rekan kerja mempunyai peran yang cukup penting dalam pencapaian tujuan perusahaan dan mempunyai pengaruh terhadap kinerja karyawan lainnya, karena rekan kerja merupakan bagian yang tak terpisahkan dalam hubungan kerja di perusahaan 


\section{Hubungan Insentif dengan Kinerja Bidan Desa dalam Pelayanan ANC}

Hasil penelitian variabel insentif dengan kategori ada dan kinerja bidan desa baik sebesar 39,5\%. Uji statistik dengan uji Chi-Square diperoleh bahwa nilai p $(0,191)>\alpha$ $(0,05)$ berarti tidak ada hubungan insentif dengan Kinerja Bidan Desa dalam pelayanan ANC di Wilayah Kerja Puskesmas Pasar Ujung Batu Kabupaten Padang Lawas. Mengacu pada hasil uji tersebut dapat dijelaskan bahwa insentif yang diperoleh oleh bidan desa tidak menjadi faktor utama untuk meningkatkan kinerjanya dalam pelayanan ANC.

Insentif yaitu semua sistem perangsang yang berkenaan dengan produktivitas baik secara perorangan maupun kelompok terhadap pekerjaan yang dapat diukur apabila mereka memperoleh bayaran lebih (Moenir AS,1993). Insentif bertujuan untuk memberikan motivasi (Dessler, 2011), factor insentif berhubungan dengan reward yang dapat memicu peningkatan kinerja (Mahsun dalam Hayadi 2007). Penelitian Hayadi (2004) insentif mempunyai korelasi positif dan signifikan dengan kinerja bidan.

\section{Hubungan Pembinaan dengan Kinerja Bidan Desa dalam Pelayanan ANC}

Hasil penelitian variabel pembinaan dengan kategori ada dan kinerja bidan desa baik sebesar 33,3\%. Uji statistik dengan uji Chi-Square diperoleh bahwa nilai $\mathrm{p}$ $(0,102)>\alpha(0,05)$ berarti tidak ada hubungan pembinaan dengan Kinerja Bidan Desa dalam pelayanan ANC di Wilayah Kerja Puskesmas Pasar Ujung Batu Kabupaten Padang Lawas. Mengacu pada hasil uji tersebut dapat dijelaskan bahwa pembinaan yang diperoleh oleh bidan desa tidak menjadi faktor untuk meningkatkan kinerjanya dalam pelayanan ANC.

Supervisi (pembinaan) diartikan sebagai pengawasa atau monitoring, bimbinga yang diberikan kepada seseorang (staf). Dengan adanya pembinaan diharapkan dapat memberik motivasi kepada seseorang dalam hal ini bidan desa untuk meningkatkan kinerjanya karena dengan pembinaan merupakan salah satu bentuk perhatian atasan kepada bawahannya.

Berdasatkan kutipan Elytha (1993) dalam Syaelendra (2001) menyatakan bahwa penampilan kerja bidan di Jawa Barat, Jawa Tengah dan Sumatera Utara, menyimpulkan bahwa bidan yang mendapatkan pembinaan satu sampai lima kali dalam enam bulan mempunyai tingkat penampilan kerja (kinerja) yang lebih baik dibandingkan tanpa pembinaan.

\section{Hubungan Rasa Aman dengan Kinerja Bidan Desa dalam Pelayanan ANC}

Hasil penelitian tentang variabel rasa aman dengan kategori sangat aman dengan proporsi Kinerja Bidan Desa baik sebesar 38,5\%. Uji statistik dengan uji Chi-Square diperoleh bahwa nilai $\mathrm{p}(0,931)>\alpha(0,05)$ berarti tidak terdapat hubungan rasa aman dengan Kinerja Bidan Desa dalam pelayanan ANC di Wilayah Kerja Puskesmas Pasar Ujung Batu Kabupaten Padang Lawas.
Perasaan aman bagi seseorang dalam melakukan pekerjaannya mempunyai pengaruh terhadap kinerja seseorang. Pernyataan ini didukung teori As'ad (1987) dalam Syaelendra (2001) yang menyatakan bahwa ketentraman dalam bekerja merupakan salah satu faktor psikologis yang berpengaruh terhadap kejiwaan seseorang secara tidak langsung mempengaruhi kinerjanya. Hasil penelitian Syaelendra (2001) menunjukkan bahwa proporsi responden yang merasa aman dalam melakukan pelayanan lebih besar dibandingkan yang kurang aman. Namun secara statistik tidak ditemui hubungan yang bermakna antara rasa aman seseorang dengan kinerja bidan di desa.

Berdasarkan hasil penelitian ini juga menunjukkan bahwa dai 40 orang bidan desa diperoleh mayoritas (27 bidan desa) yang menyatakan perasaan aman dengan kondisi kerja dimana 37,0\% bidan desa memiliki kinerja yang baik. Dilihat dari hasil penelitian ini mayoritas bidan memiliki kinerja yang kurang baik baik bidan tersebut merasa sangat aman ataupun merasa aman dengan lingkungannya yakni $61,5 \%$ dan $63,0 \%$, hal ini jelas menyimpulkan bahwa rasa aman itu tidak berhubungan dengan kinerja seseorang (bidan desa).

\section{KESIMPULAN}

1. Variabel Umur dan Status Perkawinan pada karakteristik tidak berhubungan dengan kinerja bidan desa dalam pelayanan ANC sedangkan variabel berhubungan dengan kinerja bidan desa dalam pelayanan ANC.

2. Variabel penghasilan dan sosial budaya pada faktor internal tidak berhubungan dengan kinerja bidan desa dalam pelayanan ANC sedangkan variabel keterampilan berhubungan dengan kinerja bidan desa dalam pelayanan ANC.

3. Variabel insentif dan pembinaan pada faktoreksternal tidak berhubungan dengan kinerja bidan desa dalam pelayanan ANC sedangkan variabel sarana parasarana dan mitra kerja berhubungan dengan kinerja bidan desa dalam pelayanan ANC

4. Variabel rasa aman pada faktor internal tidak berhubungan dengan kinerja bidan desa dalam pelayanan ANC

5. Penghasilan dan Sarana prasarana yang dimiliki bidan desa berpengaruh terhadap kinerja bidan desa dalam pelayanan ANC. Penghasilan yang tinggi akan mempunyai kemungkinan 0,09 kali meningkatkan kinerja bidan desa dalam pelayanan ANC dibandingkan penghasilan bidan desa yang rendah. Sarana prasarana yang baik akan mempunyai kemungkinan 16,82 kali meningkatkan kinerja bidan desa dalam pelayanan ANC dibandingkan sarana prasarana bidan desa yang kurang baik

\section{SARAN}

1. Bagi Kepala Dinas Kesehatan Daerah Kabupaten Padang Lawas, perlu kiranya dilakukan upaya dalam bentuk penegasan-penegasan kepada kepala puskesmas tentang tugas dan wewenang bidan di desa agar kinerja bidan desa meningkat. 
2. Bagi Kepala Puskesmas Pasar Ujung Batu agar meningkatkan profesionalisme bidan desa melalui kegiatan seperti : pertemuan bulanan di puskesmas tentang bagaimana meningkatkan kinerja bidan, memberikan pelayanan prima kepada ibu hamil, menggerakkan posyandu bukan hanya pada imunisasi saja tetapi kembali kepada sasaran posyandu dalam hal pelayanan ANC sehingga ibu hamil melakukan pemeriksaan kehamilan secara rutin dan teratur.

3. Bagi bidan desa di wilayah kerja Puskesmas Pasar Ujung Batu agar meningkatkan kinerjanya dengan cara meningkatkan pengetahuan tentang pelayanan ANC, melengkapi sarana prasana yang mendukung, menjalin kerjasama yang baik dengan mitra kerja dan memberikan penyuluhan kepada ibu hamil tentang pentingnya pelayanan ANC untuk membiasakan ibu hamil untuk mendapatkan pelayanan ANC walaupun ibu tidak mengalami gangguan kehamilan sehingga ibu maupun janin yang dikandung tetap sehat.

\section{DAFTAR PUSTAKA}

Depkes, 1994. Buku Saku Bidan Desa, Direktorad Jenderal Pembinaan Masyarakat Direktorad bina kesehatan Keluarga, Departemen Kesehatan RI, Jakarta. 1999. Pedoman Pelayanan Kebidanan Dasar. Jakarta , 2000. Buku Panduan Pengelolaan Program Gizi Kabupaten/Kota. 2002. Ibu Sehat Bayi Sehat, Jakarta. , 2005, Panduan Pelayanan Antenatal, Jakarta.

Gibson, J, 1996, Organisasi dan Perilaku Struktur dan proses

Handerson, C., Jones, K., 2006. Buku Ajar Konsep Kebidanan (Alih Bahasa Ria Anjarwati, Renata Komala Sari, Dian Adiningsih), Jakarta : EGC.

Hasibuan, M. S. P. 2003. Organisasi dan Motivasi, Dasar Peningkatan Produktivitas. PT Bumi Aksara, Jakarta

Ilyas, 2002. Perencanaan sumber daya manusia rumah sakit. Yogyakarta: UGM Press.

, 2004. Kinerja, Teori, Penilaian dan Penelitian. Pusat Kajian Ekonomi Kesehatan FKM UI, Jakarta, 2001

Kemenkes RI. (2010). Pedoman pelayanan kehamilan. Jakarta: Kementerian Kesehatan RI 2011. Jaminan Persalinan. Jakarta 2014. Profil Indonesia Sehat 2013. Jakarta

Kusmayati Laila, 2012. Faktor-faktor yang Berhubungan dengan Kinerja Bidan dalam Kunjungan K4 pada Ibu Hamil di Puskesmas Syamtalira Bayu Kabupaten Aceh Utara Tahun 2012. Jurnal Kesehatan Masyarakat.

Kusnadi, 2003. Masalah, Kerjasama, Konflik dan Kinerja. Taroda. Malang

Manuaba, I.B.G, 2002. Ilmu Kebidanan, Penyakit Kandungan dan Keluarga Berencana, Jakarta: EGC.

Manuaba, I.A.C., Manuaba, I.B.G.F., Manuaba, I.B.G., 2009. Memahami Kesehatan Reproduksi Wanita, Jakarta : EGC.
Mardiyah, U.L., Herawati, Y.T., \& Witcahyo, E. (2013). Faktor yang berhubungan dengan pemanfaatan pelayanan antenatal oleh ibu hamil di wilayah kerja puskesmas tempurejo kabupaten jember. Magister. Universitas Jember, Jember.

Marmi, 2011. Asuhan Kebidanan Pada masa Antenatal, Yogyakarta : Pustaka Pelajar.

Mujiono, 2002. Analisis Kinerja Tenaga Pelaksana Gizi Puskesmas dan Hubungannya dengan Upaya Perbaiakan Gizi di Kabupaten Barito Selatan. Skripsi Sarjana Jurusan GMSK, Fakultas Peratanian, IPB, Gogor.

Notoatmodjo, S., 2010. Ilmu Perilaku Kesehatan, Jakarta : Rineka Cipta.

Saifuddin, 2005. Buku Acuan Praktis Maternal dan Neonatal, Jakarta : Yayasan Bina Pustaka Sarwono Prawirohardjo.

Saputra.(2010). Asuhan Antenatal. http://morningcamp.com (Diakses 12 Agustus 2015)

Setiawan, 2007. Beberapa Faktor yang Berhubungan dengan Kinerja Bidan di Desa Dalam Pertolongan Persalinan di Kabupaten Tasikmalaya. Tesis. Program Pasca Sarjana. Universitas Diponegoro. Semarang

Siagian Sondang, 1992. Organisasi, Kepemimpinan dan Perilaku. Cetakan ke 8. CV Massagung Jakarta

Simanjuntak, P.J. 2005, Manajemen dan Evaluasi Kinerja, Lembaga penerbit Fakultas Ekonomi UI, Jakarta

Siregar Nuraijah, 2013. Faktor-faktor yang memengaruhi pemanfaatan pelayanan antenatal care (anc) di wilayah kerja puskesmas Pasar Ujung Batu Kabupaten Padang Lawas Tahun 2012. Tesis. FKM USU. Medan

Sujudi, 2001. Enam Kesepakatan menuju Desentralisasi Kesehatan. Rapat Koordinasi Terbatas Bidang Kesehatan. Jakarta.

Sumiati, Sutedja, Husin. Pengaruh Penerapan Prosedur Kerja Terhadap Peningkatan Kinerja Bidan Desa dalam Pelayanan Kebidanan di Kabupaten Sukabumi (Studi Intervensi Prosedur Kerja Bidan Desa). Artikel Penelitian. Program Studi Magister Kebidanan. Fakultas Kedokteran Universitas Padjadjaran.

Surani Endang, 2008. Analisis Karakteristik Individu dan Faktor Intrinsik yang Berhubungan dengan Kinerja Bidan Pelaksana Poliklinik Kesehatan Dasar di Kabupaten Kendal Tahun 2007. Tesis. Program Pascasarjana. Universitas Diponegoro. Semarang.

Wiknjosastro, H., 2005. Ilmu Kebidanan, Yogyakarta: Yayasan Bina Pustaka Sarwono Prawiroharjo.

Winarni, 2007. Faktor-faktor yang berhubungan dengan Peranan Bidan Desa dalam Upaya Menurunkan Angka Kematian Ibu di Kabupaten Aceh Utara Tahun 2007. Tesis. Sekolah Pascasarjana. USU. Medan.

Yasril, Kasjono, H.S., 2008. Analisis Multivariat Untuk Penelitian Kesehatan, Yogyakarta : Mitra Cendikia Press. 